\title{
25 years of remote ischemic conditioning: from laboratory curiosity to clinical outcome
}

\author{
Gerd Heusch $^{1}$
}

Published online: 7 March 2018

c) Springer-Verlag GmbH Germany, part of Springer Nature 2018

It is now 25 years ago that Przyklenk et al. first reported the phenomenon of remote ischemic preconditioning [20]. They were intrigued by infarct size reduction through ischemic preconditioning [19] and had hypothesized from a mathematical model that a preconditioning cycle of ischemia/ reperfusion might initiate a protective signal/molecule which could diffuse over a certain distance [25]. Indeed, in anesthetized dogs, they demonstrated that four cycles of $5 \mathrm{~min}$ left circumflex coronary artery occlusion/ $5 \mathrm{~min}$ reperfusion reduced the infarct size resulting from $60 \mathrm{~min}$ left anterior descending coronary artery occlusion/reperfusion [20]. Initially, such ischemic conditioning interaction between two adjacent coronary vascular perfusion territories seemed like a laboratory curiosity. However, then the paradigm of "cardioprotection at a distance" by ischemic conditioning was quickly extended to other organs and tissues and to longer distances from the heart.

McClanahan et al. reported reduction of infarct size in rabbits by prior renal ischemia/reperfusion [17], and Birnbaum et al. showed that ischemic skeletal muscle could also initiate infarct size reduction in rabbit hearts [1]. Numerous experimental studies in a variety of species and models since have established remote ischemic conditioning as a robust phenomenon. Remote ischemic conditioning before sustained myocardial ischemia/reperfusion (remote ischemic preconditioning), during ongoing coronary occlusion before reperfusion (remote ischemic perconditioning) and during early reperfusion following sustained myocardial ischemia (remote ischemic postconditioning) reduces infarct size. Protection at a distance is not only elicited by ischemia/

This comment refers to the article available at https://doi. org/10.1007/s00395-018-0672-3.

Gerd Heusch

gerd.heusch@uk-essen.de

1 Institute for Pathophysiology, West German Heart and Vascular Center, University of Essen Medical School, Essen, Germany reperfusion, but also by electrical or chemical activation of peripheral sensory nerves, and remote conditioning not only protects the heart but also other parenchymal organs from ischemia/reperfusion [9]. The signal transduction of remote ischemic conditioning is quite complex and not clear in its details, but involves activation of peripheral sensory nerves, both neuronal and humoral transfer of a cardioprotective signal from the stimulus site to the target organ, and finally in the heart an intracellular signal transduction which is largely similar to that of local ischemic pre- and postconditioning $[7,15]$.

The remote ischemic conditioning paradigm has then been quickly translated to humans (Fig. 1). Kharbanda et al. demonstrated in healthy volunteers that brief cycles of blood pressure cuff inflation/deflation on the forearm protected the contralateral arm from endothelial dysfunction and impaired vasomotion after more sustained ischemia/reperfusion [13]. Hausenloy et al. were the first to translate remote ischemic conditioning to the human heart. They used the setting of ischemic cardioplegic arrest under cardiopulmonary bypass in patients undergoing surgical coronary revascularization and reported attenuated postoperative troponin release as a surrogate for less myocardial injury with remote ischemic preconditioning by 3 cycles of $5 \mathrm{~min}$ blood pressure cuff inflation/5 min deflation on the forearm [6]. Their findings were subsequently confirmed and extended to improved clinical outcome during follow-up, but only in retrospective analyses and only in patients who had undergone surgical coronary revascularization under isoflurane anesthesia [14, 24]. The benefits from remote ischemic preconditioning during cardiovascular surgery were not confirmed in two large phase III trials, neither for troponin release nor for clinical outcome $[4,18]$, but these trials had a number of problems [8], notably the use of propofol anesthesia which is known to interfere with remote ischemic conditioning $[10,16,26]$. More importantly than for cardiovascular surgery where hypothermia and cardioplegia are anyway used for cardioprotection is the adjunct cardioprotection by remote ischemic 


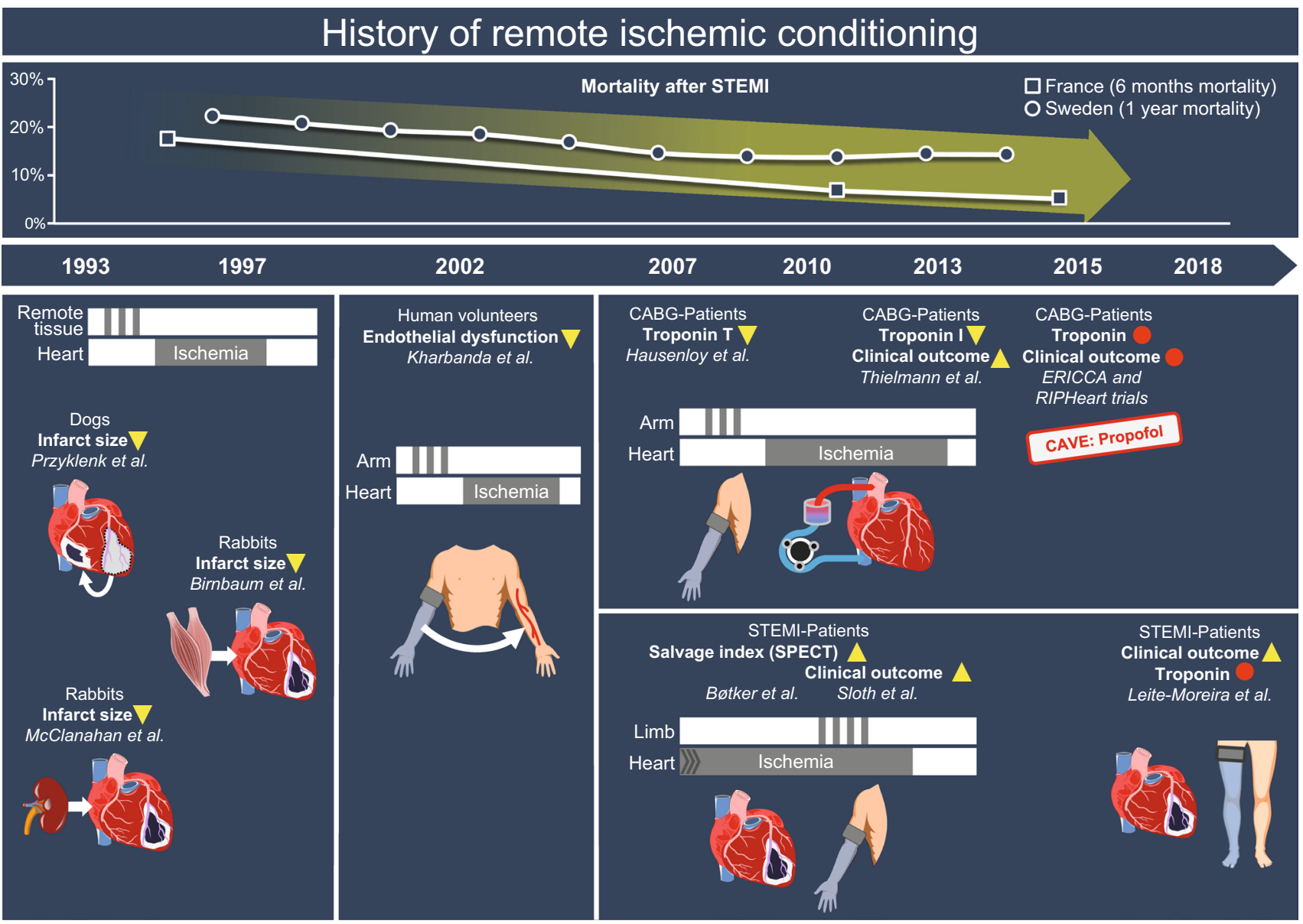

Fig. 1 Schematic diagram on the evolution of the remote ischemic conditioning paradigm over 25 years. This evolution is contrasted to the continuous improvement in standard care, as evidenced by the

conditioning in patients with acute myocardial infarction [11]. Botker et al. first used remote ischemic perconditioning in patients with acute ST segment elevation myocardial infarction (STEMI) and inflated/deflated repeatedly a blood pressure cuff on the forearm during the patients' transport to the hospital where they underwent interventional reperfusion and had eventually reduced infarct size on SPECT imaging [2]. Adjunct cardioprotection by remote ischemic perconditioning in patients with acute STEMI is not seen in all, but the majority of smaller proof-of-concept clinical trials since [12]. Sloth et al. also reported better clinical outcome in patients with STEMI when undergoing remote ischemic perconditioning, but this was only a retrospective analysis [22]. What is missing so far is a prospective, randomized clinical trial in patients with acute myocardial infarction for remote ischemic perconditioning with clinical outcome as the primary endpoint.

Now, the RIC-STEMI trial which is reported in the current issue of Basic Research in Cardiology [3] is indeed the first trial to demonstrate improved clinical outcome by reduced mortality from acute STEMI in France [21] and Sweden [23], thus making it increasingly difficult to demonstrate a benefit from remote ischemic conditioning

remote ischemic conditioning in patients with reperfused STEMI. More specifically, more than 500 patients admitted to the catheterization laboratory for STEMI were randomized to sham or three cycles of $5 \mathrm{~min}$ lower limb ischemia by blood pressure cuff inflation and 5 min reperfusion on arrival and $10 \mathrm{~min}$ before PCI. The primary endpoint was a combination of cardiac death and hospitalization for heart failure over a minimum follow-up of 12 months. The primary endpoint was significantly reduced, as were both components of it separately. Among the secondary endpoints, acute heart failure and the need for diuretics and inotropes were also reduced, and ejection fraction (echocardiography) after 12 months was improved in patients with initially low ejection fraction. Notably, the troponin I area under the curve over $48 \mathrm{~h}$ was not reduced. In addition, non-cardiac mortality and MACCE were not reduced.

The RIC-STEMI trial is important because it is the first to provide evidence for cardioprotection by remote ischemic conditioning with clinical outcome as the primary endpoint in patients with STEMI. While RIC-STEMI is important, it 
does not remain without critique. The exclusion of a number of patients after randomization makes the analysis of this trial more a per-protocol rather than an intention-to-treat analysis. Hospitalization for heart failure is not really a hard endpoint, but cardiac death was also reduced on separate analysis as a secondary endpoint. The lack of decrease in all-cause mortality and in MACCE remains unexplained. The analysis of the ejection fraction data which shows improvement by remote ischemic perconditioning in patients with low initial function over time is somewhat sensitive to "regression to the mean" effects. From a conceptual point of view, the greatest concern is the lack of reduction in troponin release-so from what does remote ischemic perconditioning actually protect, from the immediate myocardial ischemia/reperfusion injury or from subsequent deleterious remodeling? The authors honestly acknowledge these limitations and thus open the avenue for further clinical studies on this important and challenging topic. We are awaiting the results of the CONDI 2/ERIC-PPCI trial in the near future [5].

\section{References}

1. Birnbaum Y, Hale SL, Kloner RA (1997) Ischemic preconditioning at a distance. Reduction of myocardial infarct size by partial reduction of blood supply combined with rapid stimulation of the gastrocnemius muscle in the rabbit. Circulation 96:1641-1646. https://doi.org/10.1161/01.CIR.96.5.1641

2. Bøtker HE, Kharbanda R, Schmidt MR, Bottcher M, Kaltoft AK, Terkelsen CJ, Munk K, Andersen NH, Hansen TM, Trautner S, Lassen JF, Christiansen EH, Krusell LR, Kristensen SD, Thuesen L, Nielsen SS, Rehling M, Sorensen HT, Redington AN, Nielsen TT (2010) Remote ischaemic conditioning before hospital admission, as a complement to angioplasty, and effect on myocardial salvage in patients with acute myocardial infarction: a randomised trial. Lancet 375:727-734. https://doi.org/10.1016/ S0140-6736(09)62001-8

3. Gaspar A, Lourenço AP, Álvares Pereira M, Azevedo P, RonconAlbuquerque R Jr, Marques J, Leite-Moreira AF (2018) Randomized controlled trial of remote ischemic conditioning in STelevation myocardial infarction as adjuvant to primary angioplasty (RIC-STEMI). Basic Res Cardiol. https://doi.org/10.1007/s0039 5-018-0672-3 (in press)

4. Hausenloy DJ, Candilio L, Evans R, Ariti C, Jenkins DP, Kolvekar S, Knight R, Kunst G, Laing C, Nicholas J, Pepper J, Robertson S, Xenou M, Clayton T, Yellon DM, Investigators ET (2015) Remote ischemic preconditioning and outcomes of cardiac surgery. N Engl J Med 373:1408-1417. https://doi.org/10.1056/NEJMoa1413534

5. Hausenloy DJ, Kharbanda R, Rahbek Schmidt M, Moller UK, Ravkilde J, Okkels Jensen L, Engstrom T, Garcia Ruiz JM, Radovanovic N, Christensen EF, Sorensen HT, Ramlall M, Bulluck H, Evans R, Nicholas J, Knight R, Clayton T, Yellon DM, Botker HE (2015) Effect of remote ischaemic conditioning on clinical outcomes in patients presenting with an ST-segment elevation myocardial infarction undergoing primary percutaneous coronary intervention. Eur Heart J 36:1846-1848

6. Hausenloy DJ, Mwamure PK, Venugopal V, Harris J, Barnard M, Grundy E, Ashley E, Vichare S, Di Salvo C, Kolvekar S, Hayward M, Keogh B, MacAllister RJ, Yellon DM (2007) Effect of remote ischaemic preconditioning on myocardial injury in patients undergoing coronary artery bypass graft surgery: a randomized controlled trial. Lancet 370:575-579. https://doi. org/10.1016/S0140-6736(07)61296-3

7. Heusch G (2015) Molecular basis of cardioprotection: signal transduction in ischemic pre-, post-, and remote conditioning. Circ Res 116:674-699. https://doi.org/10.1161/CIRCRESAHA .116 .305348

8. Heusch G (2017) Critical issues for the translation of cardioprotection. Circ Res 120:1477-1486. https://doi.org/10.1161/ CIRCRESAHA.117.310820

9. Heusch G, Botker HE, Przyklenk K, Redington A, Yellon DM (2015) Remote ischemic conditioning. J Am Coll Cardiol 65:177-195. https://doi.org/10.1016/j.jacc.2014.10.031

10. Heusch G, Gersh BJ (2016) ERICCA and RIPHeart: two nails in the coffin for cardioprotection by remote ischemic conditioning? Probably not! Eur Heart J 37:200-202. https://doi.org/10.1093/ eurheartj/ehv606

11. Heusch G, Gersh BJ (2017) The pathophysiology of acute myocardial infarction and strategies of protection beyond reperfusion: a continual challenge. Eur Heart J 38:774-784. https://doi. org/10.1093/eurheartj/ehw224

12. Heusch G, Rassaf T (2016) Time to give op on cardioprotection? A critical appraisal of clinical studies on ischemic pre-, post-, and remote conditioning. Circ Res 119:676-695. https://doi. org/10.1161/CIRCRESAHA.116.308736

13. Kharbanda RK, Mortensen UM, White PA, Kristiansen SB, Schmidt MR, Hoschtitzky JA, Vogel M, Sorensen K, Redington AN, MacAllister AF (2002) Transient limb ischemia induces remote ischemic preconditioning in vivo. Circulation 106:28812883. https://doi.org/10.1161/01.CIR.0000043806.51912.9B

14. Kleinbongard P, Peters J, Jakob H, Heusch G, Thielmann M (2018) Persistent survival benefit from remote ischemic preconditioning in patients undergoing coronary artery bypass surgery. J Am Coll Cardiol 71:251-262. https://doi.org/10.1016/j. jacc.2017.10.083

15. Kleinbongard P, Skyschally A, Heusch G (2017) Cardioprotection by remote ischemic conditioning and its signal transduction. Pflugers Arch Eur J Physiol 469:159-181. https://doi. org/10.1007/s00424-016-1922-6

16. Kottenberg E, Thielmann M, Bergmann L, Heine T, Jakob H, Heusch G, Peters J (2012) Protection by remote ischaemic preconditioning during coronary artery bypass grafting with isoflurane but not with propofol anesthesia-a clinical trial. Acta Anaesthesiol Scand 56:30-38. https://doi.org/10.111 1/j.1399-6576.2011.02585.x

17. McClanahan TB, Nao BS, Wolke LJ, Martin BJ, Mertz TE, Gallagher KP (1993) Brief renal occlusion and reperfusion reduces myocardial infarct size in rabbits. Faseb J 7:A118

18. Meybohm P, Bein B, Brosteanu O, Cremer J, Gruenewald M, Stoppe C, Coburn M, Schaelte G, Boning A, Niemann B, Roesner J, Kletzin F, Strouhal U, Reyher C, Laufenberg-Feldmann R, Ferner M, Brandes IF, Bauer M, Stehr SN, Kortgen A, Wittmann M, Baumgarten G, Meyer-Treschan T, Kienbaum P, Heringlake M, Schon J, Sander M, Treskatsch S, Smul T, Wolwender E, Schilling T, Fuernau G, Hasenclever D, Zacharowski K, Collaborators RIS (2015) A multicenter trial of remote ischemic preconditioning for heart surgery. $\mathrm{N}$ Engl $\mathrm{J}$ Med 373:1397-1407. https://doi.org/10.1056/NEJMoa1413579

19. Murry CE, Jennings RB, Reimer KA (1986) Preconditioning with ischemia: a delay of lethal cell injury in ischemic myocardium. Circulation 74:1124-1136. https://doi.org/10.1161/01. CIR.74.5.1124

20. Przyklenk K, Bauer B, Ovize M, Kloner RA, Whittaker P (1993) Regional ischemic "preconditioning" protects remote virgin myocardium from subsequent sustained coronary 
occlusion. Circulation 87:893-899. https://doi.org/10.1161/01. CIR.87.3.893

21. Puymirat E, Simon T, Cayla G, Cottin Y, Elbaz M, Coste P, Lemesle G, Motreff P, Popovic B, Khalife K, Labeque JN, Perret T, Le Ray C, Orion L, Jouve B, Blanchard D, Peycher P, Silvain J, Steg PG, Goldstein P, Gueret PJ, Belle L, Aissaoui N, Ferrieres J, Schiele F, Danchin N, Usik U, Investigators F-M (2017) Acute myocardial infarction: changes in patient characteristics, management, and 6-month outcomes over a period of 20 years in the FAST-MI Program (French Registry of Acute ST-Elevation or Non-ST-elevation Myocardial Infarction) 1995 to 2015. Circulation. https://doi.org/10.1161/CIRCULATIONAHA.117.030798

22. Sloth AD, Schmidt MR, Munk K, Kharbanda RK, Redington AN, Schmidt M, Pedersen L, Sorensen HT, Bøtker HE (2014) Improved long-term clinical outcomes in patients with ST-elevation myocardial infarction undergoing remote ischaemic conditioning as an adjunct to primary percutaneous coronary intervention. Eur Heart J 35:168-175. https://doi.org/10.1093/eurheartj/ eht 369

23. Szummer K, Wallentin L, Lindhagen L, Alfredsson J, Erlinge D, Held C, James S, Kellerth T, Lindahl B, Ravn-Fischer A, Rydberg E, Yndigegn T, Jernberg T (2017) Improved outcomes in patients with ST-elevation myocardial infarction during the last 20 years are related to implementation of evidence-based treatments: experiences from the SWEDEHEART registry 1995-2014. Eur Heart J 38:3056-3065. https://doi.org/10.1093/eurheartj/ehx515

24. Thielmann M, Kottenberg E, Kleinbongard P, Wendt D, Gedik N, Pasa S, Price V, Tsagakis K, Neuhäuser M, Peters J, Jakob H, Heusch G (2013) Cardioprotective and prognostic effects of remote ischaemic preconditioning in patients undergoing coronary artery bypass surgery: a single-centre randomised, double-blind, controlled trial. Lancet 382:597-604. https://doi.org/10.1016/ S0140-6736(13)61450-6

25. Whittaker P, Przyklenk K (1994) Reduction of infarct size in vivo with ischemic preconditioning: mathematical evidence for protection via non-ischemic tissue. Basic Res Cardiol 89:6-15

26. Zangrillo A, Musu M, Greco T, Di Prima AL, Matteazzi A, Testa V, Nardelli P, Febres D, Monaco F, Calabro MG, Ma J, Finco G, Landoni G (2015) Additive effect on survival of anaesthetic cardiac protection and remote ischemic preconditioning in cardiac surgery: a Bayesian network meta-analysis of randomized trials. PLoS One 10:e0134264. https://doi.org/10.1371/journ al.pone. 0134264 